\title{
Nuclear Magnetic Resonance Analysis of Water Absorption Characteristics and Dynamic Changes in Pore Size Distribution of Wood-plastic Composites
}

\author{
Qiang Jin, ${ }^{\mathrm{a}, *}$ Lin $\mathrm{Zhu},{ }^{\mathrm{a}} \mathrm{Di} \mathrm{Hu},{ }^{\mathrm{a}}$ Chunxia $\mathrm{He},{ }^{\mathrm{b}}$ and $\mathrm{Li} \mathrm{Li}{ }^{\mathrm{a}}$ \\ Low-field nuclear magnetic resonance (NMR) technology was used to \\ perform the experiments of transverse relaxation time $\left(T_{2}\right)$, pore size \\ distribution, and water absorption rate for wood-plastic composites (WPC) \\ with different contents of added slag powder, exploring the water \\ movement and the dynamic changes of pore size during the moisture \\ absorption process of the material under immersion condition. The \\ experimental results were as follows: (1) According to the $T_{2}$ of $\mathrm{H}$ proton \\ and its inversion pattern, the measured porosity had a relatively small \\ difference from that of the weighing method. (2) The pore size distribution \\ graph showed the following: (i) when the immersion time of composite \\ materials was different, the changing law of volume of pores with different \\ radius was different.; (ii) when the material's immersion time was greater \\ than $216 \mathrm{~h}$, the pore radius and its distribution characteristics showed \\ large differences; (iii) slag powder changed the pore structure of the WPC \\ but did not change the water absorption characteristics of the wheat straw. \\ (3) The changes of water absorption and expansion rate showed that the \\ slag powder changed the time for the materials' pores to absorb water until \\ saturation and reduced the water absorption and expansion rate. The \\ measurement results were consistent with changing trend in the pore size \\ obtained by low-field NMR relaxometry.
}

Keywords: Wood-plastic composite; Low-field NMR; Water absorption; Pore size distribution; Slag powder

Contact information: a: College of Hydraulic and Civil Engineering, Xinjiang Agricultural University, Urumqi, Xinjiang 830052, People's Republic of China; $b$ : College of Engineering, Nanjing Agricultural University, Nanjing 210031, China; *Corresponding author: xjnydxjq@126.com

\section{INTRODUCTION}

Wood-plastic composites (WPCs) are widely used and have a wood-like texture. They generally have better water resistance than solid wood and contain a certain amount of wood fiber. Although the composite generally does not have a high wood fiber content and is covered by plastic, it still has a distinct water absorption capacity. After the WPC absorbs water, it is prone to a series of undesirable consequences, such as volume deformation, decrease in mechanical properties, and mildew (Najafi et al. 2006; Defoirdt et al. 2010). Therefore, studying the water absorption pattern of WPCs and analyzing the water transport in the pores and its influence are vital to the research, production, and application of WPCs.

The existing studies have focused on changing the composite coating effect and interface compatibility; reducing the water transport effect at the interface and in the fiber; and altering the WPC water resistance, mainly by regulating the wood fiber content (Lin et al. 2020), adding inorganic micropowder (Qi et al. 2019), heat treatment (Kaboorani and 
Englund 2011), and introducing a coupling agent (Zhuo et al. 2020). Some researchers (Zhao et al 2020) used the co-extrusion technique to prepare co-extruded WPCs (including a shell layer and a core layer) and conducted measurements. The results showed that the composites prepared by the co-extrusion technique had better dimensional stability and mechanical properties. Cheng and Shaler (2010) compared the differences in water movement among extruded WPCs under the actions of high humidity, freshwater, and seawater; they determined the moisture diffusion coefficient of the thin sample under high humidity and that of small cubic samples immersed in distilled water and seawater. The results showed that the diffusion coefficient of the thin sample was higher than the moisture movement rate in the extruded profile, indicating that the material featured other transport phenomena besides diffusion. In the study of the microscopic pore structure of WPCs, Ismaeilimoghadam et al. (2016) used scanning electron microscopy (SEM) to analyze the effects of $\mathrm{SiO}_{2}$ and $\mathrm{TiO}_{2}$ nanoparticles on the mechanical properties and particle distribution pattern of WPCs. The results showed that the nanoparticles had an appropriate dispersibility at $1 \%$ and $3 \%$. When the WPC was mixed with $5 \mathrm{wt} \%$ nanoparticles, the particles could aggregate on the composite substrate, causing a significant decrease in strength. Kallbom et al. (2020) used modified wood to prepare thermoplastic composites and analyzed the water migration behavior of the samples, as well as the resulting changes in macro-size and micro-morphology, through a water soaking-drying cycle measurement. The results showed that the water absorption rate of the modified wood-thermoplastic composite decreased considerably.

The mercury intrusion method is a common technique for characterizing the pore structures of materials. Some researchers have found that under high pressures, the pore structure of cement-based materials may change drastically (Wang et al. 2017; Zhou et al. 2018). Wang et al. (2019) and Muller and Scrivener (2017) used X-ray computed tomography and nuclear magnetic resonance (NMR) to study the changes in the pore structure of cement paste before and after mercury intrusion; the results showed that the material pore structures before and after mercury intrusion were different. Diamond (2000) has pointed out that the mercury intrusion method is only suitable for measuring the threshold diameter and intrudable pore space, not for measuring the actual pore diameter. For the pores in WPCs, the pore size changes will be more distinct under the high pressure of the mercury intrusion method. In this regard, it has been shown that low-field nuclear magnetic resonance (LF-NMR) spectroscopy can be used to non-destructively study the pore structure of porous materials based on the relaxation properties of water molecules (Korb 2009; Sun and Scherer 2010; Zhao et al. 2018).

The porosity and water absorption properties of WPCs have always been key research topics (Homkhiew et al. 2014). The water movement in the pores is closely related to the wood fiber properties, and the pores and water absorption are the main factors affecting the composite properties. Variations in the moisture content can change the pore size of wood fibers, and the pore size will further affect the water movement. Previous studies have mainly analyzed the relationship between pores and water absorption from a macroscopic perspective. The studies on changes in pore size during water absorption, especially the changes in water migration and the resulting pore, are few. For this reason, this study employed the LF-NMR technique and used the nuclear magnetic relaxation characteristics of protons to explore the material pores and water movement in the pores from the perspective of nuclear magnetic dynamics. The study aimed to provide new ideas for the investigation of water movement in heterogeneous porous materials and provide a theoretical basis and data support for the modification of WPCs. 


\section{EXPERIMENTAL}

\section{Main Raw Materials}

The materials were as follows: Polyvinyl chloride (PVC) resin, SG-5, Xinjiang Tianye Co., Ltd., Shihezi, China; wheat straw fiber, homemade, Wujiaqu City, China, particle size less than $180 \mu \mathrm{m}$; steel slag powder $(\mathrm{G})$, a by-product of the steelmaking process, Baosteel Group Xinjiang Bayi Iron and Steel Co., Ltd., Ürümqi, China, hot braised steel slag was selected in this experiment and ground with a ball mill for 20 min to reach a prescriptive fineness (specific surface area was 425 to $500 \mathrm{~m}^{2} / \mathrm{kg}$ ). The main property indicators of steel slag powder are shown in Table 1. Slag powder (K) was a by-product of the convection furnace ironmaking process, Baosteel Group Xinjiang Bayi Iron and Steel Co., Ltd., Ürümqi, China. The steel-making pig iron quenching slag was selected in this experiment and ground with a ball mill for $30 \mathrm{~min}$ to reach a prescriptive fineness (specific surface area was $400 \pm 5 \mathrm{~m}^{2} / \mathrm{kg}$ ). The main property indicators of slag powder are shown in Table 1; silane coupling agent: KH-550, Nanjing Herun Coupling Agent Co., Ltd., Nanjing, China.

Table 1. Main Performance Indicators of Steel Slag and Slag Powder

\begin{tabular}{|c|c|c|c|c|c|c|c|c|}
\hline $\begin{array}{c}\text { Inorganic } \\
\text { Powder } \\
\text { Sample Label }\end{array}$ & $\begin{array}{c}\text { Surface Area } \\
\left(\mathrm{m}^{2} / \mathrm{g}\right)\end{array}$ & \multirow{2}{*}{$\begin{array}{c}\text { Density } \\
\left(\mathrm{g} / \mathrm{cm}^{3}\right)\end{array}$} & \multicolumn{6}{|c|}{ Chemical Composition (\%) } \\
\cline { 5 - 10 } & $\mathrm{SiO}_{2}$ & $\mathrm{Al}_{2} \mathrm{O}_{3}$ & $\mathrm{CaO}$ & $\mathrm{TFe}$ & $\mathrm{MgO}$ & $\mathrm{f}-\mathrm{CaO}$ \\
\hline $\mathrm{G}$ & $429 \pm 5$ & 3.37 & 13.11 & 3.05 & 42.65 & 17.50 & 8.85 & 1.24 \\
\hline $\mathrm{K}$ & $440 \pm 5$ & 2.86 & 36.37 & 10.29 & 41.5 & 0.25 & 7.43 & - \\
\hline
\end{tabular}

\section{Main Instruments and Equipment}

The MesoMR23-060H-1 nuclear magnetic analyzer was manufactured by Suzhou Niumag Analytical Instrument Co., Ltd. (Shanghai, China). The test parameters were as follows: resonance frequency $23.404928 \mathrm{MHz}$, magnetic field strength $0.5 \mathrm{~T}$, coil diameter $60 \mathrm{~mm}$, and magnet temperature $32.00{ }^{\circ} \mathrm{C}$; field-emission environmental scanning electron microscope: Quanta FEG250 (FEI, Hillsboro, OR, USA).

\section{Experimental Parameters}

A Carr-Purcell-Meiboom-Gill sequence was adopted for LF-NMR samples: SFO1 $(\mathrm{MHz})=23.0409, \mathrm{P} 90(\mu \mathrm{s})=11, \mathrm{P} 180(\mu \mathrm{s})=23.04, \mathrm{SW}(\mathrm{KHz})=200$, TW $(\mathrm{ms})=6000$, $\mathrm{TE}(\mathrm{ms})=0.2, \mathrm{RG} 1=20, \mathrm{DRG} 1=3, \mathrm{PRG}=3, \mathrm{NECH}=18000$, and $\mathrm{NS}=32$. According to the material mixing ratio in Table 2 , the following materials were weighed and mixed: the steel slag and slag micropowder modified by the silane coupling agent, the dried wheat straw fiber, the PVC, and other additives.

Table 2. Mixing Ratio of Composites (Mass Ratio)

\begin{tabular}{|c|c|c|c|c|}
\hline Label & $\begin{array}{c}\text { Wheat Straw } \\
(\mathrm{wt} \%)\end{array}$ & PVC (wt\%) & $\begin{array}{c}\text { Slag Powder } \\
(\mathrm{wt} \%)\end{array}$ & Steel Slag Powder (wt\%) \\
\hline $\mathrm{K} \# 0$ & 35 & 100 & 0 & 0 \\
\hline $\mathrm{K} \# 5$ & 35 & 100 & 5 & 0 \\
\hline $\mathrm{K} \# 10$ & 35 & 100 & 10 & 0 \\
\hline $\mathrm{K} \# 15$ & 35 & 100 & 15 & 0 \\
\hline $\mathrm{G} \# 15$ & 35 & 100 & 0 & 15 \\
\hline
\end{tabular}


The prepared mixture was placed into a three-dimensional mechanical linkage mixer and mixed for $10 \mathrm{~min}$. Next, the composite sample was extruded through a conical twin-screw extruder, and the temperature range of the extruder was adjusted to 175 to 185 ${ }^{\circ} \mathrm{C}$. The temperature range of the four zones of the extruder was adjusted between 145 and $155^{\circ} \mathrm{C}$. The head pressure was $5 \mathrm{MPa}$, and the motor speed was adjusted to $15 \mathrm{r} / \mathrm{min}$. The sample size is $100 \mathrm{~mm} \times 10 \mathrm{~mm} \times 7 \mathrm{~mm}$, and three duplicate samples are used for each group.

\section{Measurement Method}

(1) Detection of protons: The sample was placed in a magnetic field. Radiofrequency $(\mathrm{RF})$ pulse at the necessary frequency was emitted to make the protons resonate, and the protons absorbed the RF pulse energy. When the RF pulse stops, the protons will release the absorbed RF energy. For samples with different properties, the energy release rates are different, and the patterns can be found through these signals to study the samples' internal properties. CPMG pulse sequence based on improved SE (spin echo) pulse sequence detected multiple echo strings in one measurement, which greatly improves the measurement accuracy and shortens the measurement time (Grunewald and Walsh 2013). In this work, the samples with different water absorption time were tested by CPMG pulse sequence, and the SE attenuation signals superposed in pores with different sizes were obtained. The T2 spectrum of NMR transverse relaxation time was obtained by Fourier transform fitting, and the change distribution of T2 spectrum reflected the change of material moisture. Low-field nuclear magnetic resonance was used to analyze the specimen. The $\mathrm{T}_{2}$ spectrum and the mass of absorbed water were linearly fitted, and the relationship between the two was analyzed.

(2) Pore size distribution: According to the NMR relaxation mechanism, for porous materials, the transverse relaxation rate, $1 / \mathrm{T}_{2}$, of the fluid in the pores can be approximately expressed as

$$
1 / T_{2}=\rho_{2}(S / V) \text { porosity }
$$

where $S$ is the pore surface area $\left(\mathrm{cm}^{2}\right) ; V$ is the pore volume $\left(\mathrm{cm}^{3}\right)$; and $\rho_{2}$ is the transverse relaxivity $(\mu \mathrm{m} / \mathrm{ms})$.

As shown in Eq. 1, the $T_{2}$ value of WPCs was mainly determined by the material $\left(\rho_{2}\right)$ and the ratio of pore surface to volume. The pore structure shape can be simplified to a sample with spherical or cylindrical pores. Equation 1 can be further converted into the relationship between $T_{2}$ relaxation time and pore radius, as follows,

$$
1 / T_{2}=\left(\rho_{2} / r\right) F_{s}
$$

where $r$ is the pore radius $(\mu \mathrm{m})$, and $F_{s}$ is the geometric shape factor (spherical pores, $F_{s}=$ 3; cylindrical pores, $\left.F_{s}=2\right)$.

Therefore, the $T_{2}$ spectrum reflects the pore size and the pore size distribution of the material. The pore size is related to the peak position in the spectrum, and the number of pores corresponding to the pore size is related to the peak area. According to Eqs. 1 and 2 , the pore radius is positively correlated with the $T_{2}$ value: the smaller the $T_{2}$ value, the smaller the pore size; the larger the pore size, the larger the $T_{2}$ value.

Water absorption by the WPC can affect the size, number, and distribution of pores inside the material. The CONTIN algorithm (Provencher 1982a,b) is used to invert the obtained $T_{2}$ data to obtain the $T_{2}$ distribution of moisture, and then calculate the pore distribution. According to Eq. 2 and the pore geometric characteristics of WPCs, the 
cylindrical pore shape factor $F_{\mathrm{s}}$ was selected, that is, 2 . Different material types have different surface relaxation strength values $\rho_{2}$. For wood-based materials with porous medium properties, the value range of $\rho_{2}$ is generally 1 to $10 \mu \mathrm{m} / \mathrm{ms}$. The $\rho_{2}$ value was set at $6 \mu \mathrm{m} / \mathrm{ms}$ in this study (Li 2017). Equation 2 can be simplified as:

$$
r=\rho_{2} T_{2} F_{s}
$$

According to Eq. 3, the $T_{2}$ spectrum distribution of the material could be converted into the pore size distribution curve. To illustrate the pore size distribution of various pores, the distribution proportion of each pore size was statistically analyzed and plotted into a distribution graph.

(3) Water absorption rate and expansion rate were determined via the weighing method: The composite was dried to constant weight and then placed in a sink to be immersed in water of room temperature $\left(23^{\circ} \mathrm{C} \pm 1^{\circ} \mathrm{C}\right)$. The sample was taken out after the set time and quickly wiped and dried with filter paper. The specimen mass was measured on a balance (precision: $0.001 \mathrm{~g}$ ), the length of the specimen was measured with a vernier caliper (precision: $0.02 \mathrm{~mm}$ ), and the data were substituted into Eqs. 4 and 5 to calculate the water absorption rate, water-absorption expansion rate, and the difference between the two,

$$
W=\left[\left(M_{\mathrm{i}}-M_{0}\right) / M_{0}\right] \times 100 \%
$$

where $W$ is the water absorption rate $(\mathrm{wt} \%) ; M_{0}$ is the specimen mass before immersion in water $(\mathrm{g}) ; M_{\mathrm{i}}$ is the specimen mass in different time periods $(\mathrm{g})$,

$$
K=\left[\left(L_{\mathrm{i}}-L_{0}\right) / L_{0}\right] \times 100 \%
$$

where $K$ is the water-absorption expansion rate $(\%) ; L_{0}$ is the specimen length before immersion in water $(\mathrm{mm})$; and $L_{\mathrm{i}}$ is the length of the immersed specimen in different time periods $(\mathrm{mm})$,

$$
\Delta=W-K
$$

where $\Delta$ is the difference between the water absorption rate and the water absorption expansion rate.

\section{RESULTS AND ANALYSIS}

\section{Relationship Between the Mass of Water Absorbed by the Composite and the Peak Area in $T_{2}$ Spectrum}

The LF-NMR measurement principle is that a proton is used as the probe to detect the change in signal strength of the $T_{2}$ spectrum during the water absorption process, and the signal strength is positively correlated with the mass of absorbed water. Figure 1 shows the relationship between the measured mass of absorbed water and the peak area in the $T_{2}$ spectrum of the K\#0 specimen, and the fitted equation of the mass of water absorbed by $\mathrm{K \# 0}$ and the peak area in the $T_{2}$ spectrum area was used as the calibration line of the composite. According to the fitted equation, the coefficient of determination $\left(\mathrm{R}^{2}\right)$ was 0.99614. Moreover, because the difference in material volume was small (that is, the initial signal strength was roughly the same), the fitted equation was used to calculate the porosity of the corresponding material. When the mass of water absorbed by $\mathrm{K \# 0}$ was 0 , the peak area in the $T_{2}$ spectrum was 1696.73 , indicating that the peak area included not only the 
signal strength of protons in water but also the signal strengths produced by protons in cellulose, hemicellulose, and lignin.

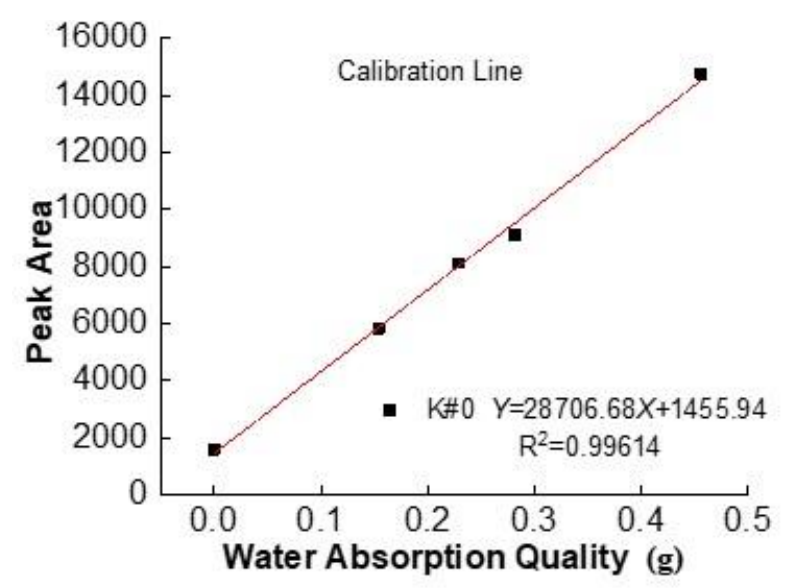

Fig. 1. The relationship between mass of water absorbed by $\mathrm{K \# 0}$ and peak area in $T_{2}$ spectrum

The regression equation of mass of the absorbed water and peak area in the $T_{2}$ spectrum is,

$$
Y=28706.68 X+1455.94
$$

where $Y$ is the peak area in the $T_{2}$ spectrum and $X$ is the NMR-measured mass of water absorbed by the composite $(\mathrm{g})$.

The NMR method was used to determine the material porosity, i.e., the ratio of the volume of water in the pore to the volume of the saturated specimen,

$$
P=\left\{\left[\left(X_{1}-X_{2}\right) / \rho_{w}\right] / V_{w}\right\} \times 100 \%
$$

where $P$ is the porosity (\%), $X_{1}$ is the water mass determined through the NMR method when the composite is saturated with water $(\mathrm{g}), X_{2}$ is the water mass determined through the NMR method when the composite is dry $(\mathrm{g}), \rho_{\mathrm{w}}$ is the water density $\left(1 \mathrm{~g} / \mathrm{cm}^{3}\right)$, and $V_{\mathrm{w}}$ is the volume of the saturated specimen $\left(\mathrm{cm}^{3}\right)$.

Table 3. Material Porosity

\begin{tabular}{|c|c|c|c|c|c|c|c|c|}
\hline Label & $\begin{array}{c}\text { Initial } \\
\text { Peak Area } \\
\text { in } T_{2} \\
\text { Spectrum }\end{array}$ & $\begin{array}{c}\text { Saturation } \\
\text { Peak Area } \\
\text { in } T_{2} \\
\text { Spectrum }\end{array}$ & $\begin{array}{c}X_{1} \\
(\mathrm{~g})\end{array}$ & $\begin{array}{c}X_{2} \\
(\mathrm{~g})\end{array}$ & $\begin{array}{c}V_{\mathrm{w}} \\
\left(\mathrm{cm}^{3}\right)\end{array}$ & $\begin{array}{c}\text { Porosity } \\
\text { Obtained } \\
\text { Using } \\
\text { NMR } \\
\text { Method } \\
(\%)\end{array}$ & $\begin{array}{c}\text { Porosity } \\
\text { Obtained } \\
\text { Using } \\
\text { Weighing } \\
\text { Method } \\
(\%)\end{array}$ & $\begin{array}{c}\text { Difference } \\
\text { of } \\
\text { Porosity } \\
(\%)\end{array}$ \\
\hline K\#0 & 1601.22 & 14775.48 & 5.22 & 4.77 & 3.76 & 12.34 & 10.68 & 1.66 \\
\hline K\#5 & 1865.36 & 12716.71 & 5.30 & 4.87 & 3.70 & 10.6 & 9.80 & 0.80 \\
\hline K\#10 & 1572.45 & 11244.90 & 5.24 & 4.84 & 3.59 & 9.48 & 8.49 & 0.99 \\
\hline K\#15 & 1397.38 & 10287.60 & 5.38 & 4.98 & 3.60 & 8.54 & 7.49 & 1.05 \\
\hline G\#15 & 625.51 & 5501.85 & 5.59 & 5.15 & 3.69 & 3.82 & 8.13 & -4.31 \\
\hline
\end{tabular}

Table 3 shows that a certain deviation existed between the porosities calculated by the NMR method and the weighing method; the porosity calculated by the NMR method was generally higher. Because the slag powder contains a small amount of TFe, which is a 
paramagnetic substance, a tiny internal magnetic field will be generated in the specimen, causing the NMR-measured signal to change. Additionally, as the slag powder content increased, a slight change was introduced in the relative content of wheat straw in the composite, affecting the initial signal strength. The porosity differences and signal strengths of K\#15 and G\#15 were compared. The porosity difference of G\#15 was found to be relatively large, and the signal strength was small. The analysis of the G\#15 composition showed that the TFe content was as high as $17.5 \%$, indicating that highcontent paramagnetic materials have a relatively great impact on the LF-NMR measurement results; thus, the LF-NMR technique is not suitable for analyzing highcontent paramagnetic composites.

\section{Influence of Immersion Time on Water Movement in WPCs}

In the $T_{2}$ relaxation-time inverted spectrum, each peak represents the same type of volume of water; the peak area is the water content of this state of water, and the highest point of the peak represents the average relaxation time of this state of water (Zhao et al. 2019). The aim of this experiment was to obtain the changes in the water migration of WPCs in different periods through an analysis of the changes in the peak area of WPCs at different immersion times.
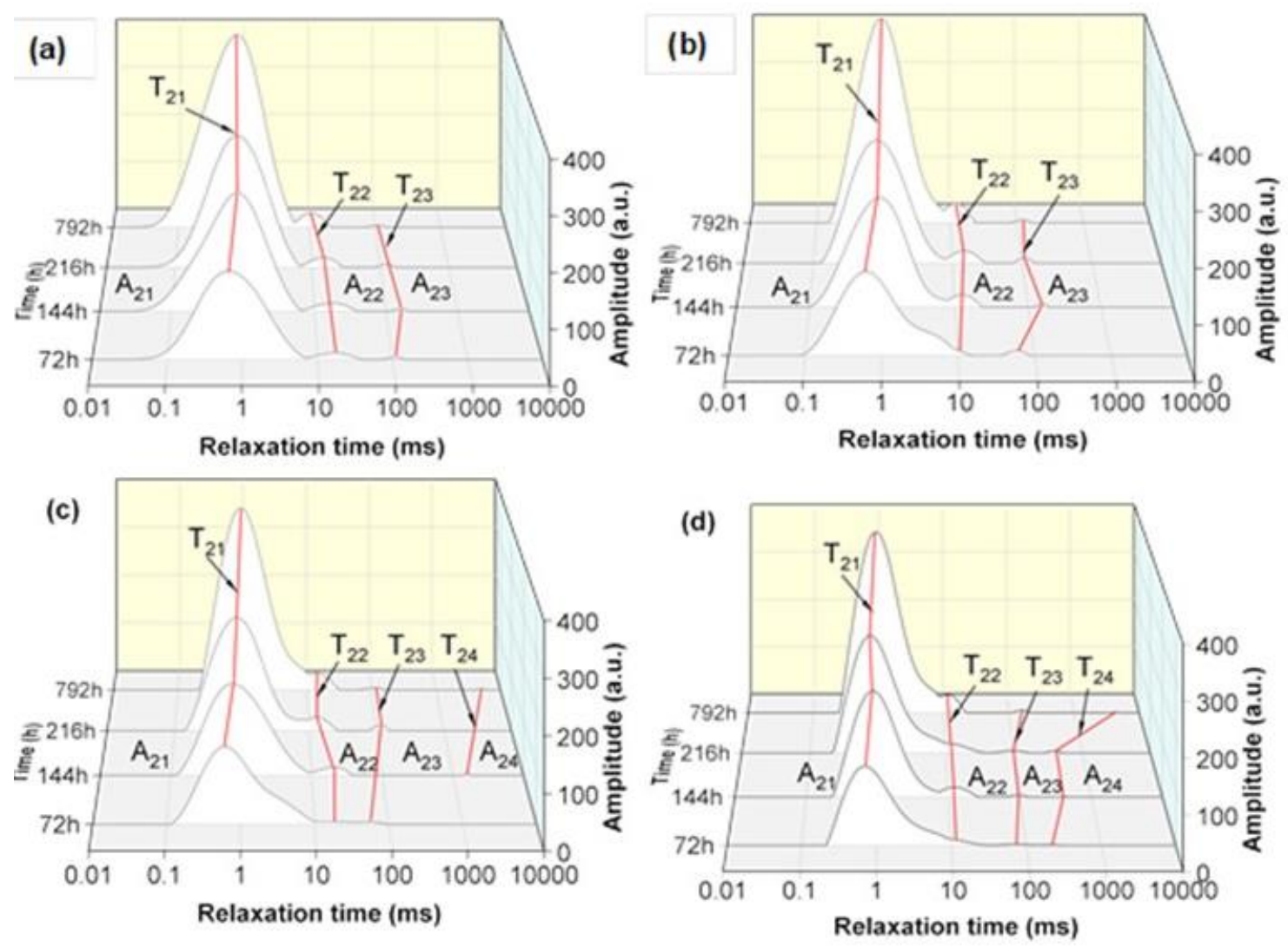

Fig. 2. $T_{2}$ relaxation time and signal amplitude of composites at different water absorption times: (a) $\mathrm{K \# 0}$, (b) K\#5, (c) K\#10, and (d) K\#15

In the experiment, $\mathrm{K} \# 0, \mathrm{~K} \# 5, \mathrm{~K} \# 10$, and $\mathrm{K} \# 15$ specimens were dried to a constant weight and then immersed in water. The LF-NMR measurement was carried out on the 
above samples at $72 \mathrm{~h}, 144 \mathrm{~h}, 216 \mathrm{~h}$, and $792 \mathrm{~h}$, respectively, and the collected signal strength was inverted to obtain the peak area in this state. Figure 2 shows the $T_{2}$ relaxation time and signal amplitude of the composite at different water absorption times. Table 4 presents the $T_{2}$ relaxation time and area of each peak.

Table 4 shows the relaxation times and peak areas of the four materials at different immersion times. As shown in Table 4, the relaxation time of $T_{21}$ was in the range of 0.69 to $0.85 \mathrm{~ms}$, and that of $T_{22}$ was in the range of 10.35 to $18.04 \mathrm{~ms}$. With increasing immersion time, $T_{21}$ and $T_{22}$ all moved within a certain range; $T_{21}$ moved in the direction of long relaxation, and $T_{22}$ moved in the direction of short relaxation; the peak areas of $T_{21}$ and $T_{22}$ were associated with $A_{21}$ and $A_{22}$, respectively, and the total peak area corresponded to $A$.

As depicted in Fig. 2, during the water absorption process of the composite mixed with slag powder, as the time increased, 3 to 4 peaks appeared in the signal intensity, and the signal intensity and distribution were different at different water absorption times. The relaxation times of $\mathrm{K \#} 0, \mathrm{~K} \# 5, \mathrm{~K} \# 10$, and $\mathrm{K} \# 15$ specimens with different water absorption times did not change, but the signal peak value and peak area featured a gradual increase, indicating that the water volume in the composite increased. The comparison of $\mathrm{K \# 0}$ and K\#15 showed that the $T_{21}$ relaxation time distribution of K\#15 was narrow, and the start time and signal peak value shifted rightward. This revealed that during the composite water absorption process, as the slag powder content increased, the pore size and distribution of the composite materials had changed.

Table 4. $T_{2}$ Relaxation Time and Peak Area

\begin{tabular}{|c|c|c|c|c|c|c|c|c|c|c|c|}
\hline $\begin{array}{l}\text { Group } \\
\text { Label }\end{array}$ & Time & $\begin{array}{c}\text { Water } \\
\text { Abs. } \\
(\%)\end{array}$ & $\begin{array}{c}T_{21} \\
(\mathrm{~ms})\end{array}$ & $\begin{array}{l}T_{22} \\
(\mathrm{~ms})\end{array}$ & $\begin{array}{c}T_{23} \\
(\mathrm{~ms})\end{array}$ & $\begin{array}{c}T_{24} \\
(\mathrm{~ms})\end{array}$ & $\begin{array}{c}A_{21} \\
\left(\mathrm{~cm}^{2}\right)\end{array}$ & $\begin{array}{c}A_{22} \\
\left(\mathrm{~cm}^{2}\right)\end{array}$ & $\begin{array}{c}A_{23} \\
\left(\mathrm{~cm}^{2}\right)\end{array}$ & $\begin{array}{c}A_{24} \\
\left(\mathrm{~cm}^{2}\right)\end{array}$ & $\begin{array}{c}A \\
\left(\mathrm{~cm}^{2}\right)\end{array}$ \\
\hline \multirow{4}{*}{$\mathrm{K \# 0}$} & 72 & 3.32 & 0.691 & 16.832 & 109.70 & - & 5618.470 & 195.780 & 24.554 & & 5838.804 \\
\hline & 144 & 5.84 & 0.85 & 18.042 & 155.22 & - & 7840.148 & 263.040 & 23.959 & & 8127.147 \\
\hline & 216 & 8.55 & 0.85 & 14.65 & 126.038 & & 8798.977 & 268.712 & 40.917 & & 9108.606 \\
\hline & 792 & 10.68 & 0.74 & 10.353 & 117.585 & & 14365.542 & 383.150 & 26.788 & & 14775.48 \\
\hline \multirow{4}{*}{ K\#5 } & 72 & 2.56 & 0.601 & - & 58.728 & - & 5043.048 & & 69.256 & & 5112.304 \\
\hline & 144 & 4.89 & 0.977 & 12.751 & 155.223 & - & 6453.791 & 266.661 & 25.203 & & 6745.655 \\
\hline & 216 & 7.12 & 0.85 & 14.65 & 109.70 & - & 7614.073 & 315.318 & 65.303 & & 7994.694 \\
\hline & 792 & 9.80 & 0.977 & 11.895 & 126.038 & - & 12216.211 & 461.043 & 39.458 & & 12716.712 \\
\hline \multirow{4}{*}{ K\#10 } & 72 & 2.13 & 0.601 & 16.832 & 54.789 & & 4447.508 & 64.588 & 51.046 & & 4563.142 \\
\hline & 144 & 4.46 & 0.74 & 20.729 & & 1534.368 & 5759.197 & 212.733 & & 9.434 & 5981.364 \\
\hline & 216 & 6.01 & 0.85 & 12.751 & 117.585 & & 6760.948 & 260.774 & 72.980 & & 7094.702 \\
\hline & 792 & 8.49 & 0.977 & 13.667 & 117.585 & 4994.505 & 10847.463 & 351.723 & 36.541 & 9.176 & 11244.903 \\
\hline \multirow{4}{*}{ K\#15 } & 72 & 1.94 & 0.691 & - & 72.326 & 219.639 & 4002.919 & & 26.646 & 8.183 & 4037.748 \\
\hline & 144 & 3.19 & 0.850 & 11.895 & 95.477 & 410.266 & 5020.929 & 372.579 & 22.996 & 1.847 & 5418.351 \\
\hline & 216 & 4.67 & 0.740 & 11.098 & 95.477 & 410.266 & 6506.708 & 206.042 & 53.022 & $\begin{array}{c}24.60 \\
0\end{array}$ & 6790.372 \\
\hline & 792 & 7.49 & 0.912 & 11.895 & 155.223 & 4357.013 & 10253.719 & 332.077 & 29.583 & 4.303 & 10619.68 \\
\hline
\end{tabular}

As presented in Table 4, as the water absorption time increased, the peak area $(A)$ of the composite continued to increase, which was consistent with the change trend of the water absorption rate (Fig. 6). The comparison of the peak areas of several materials 
showed that the area of the $A_{21}$ peak was considerably larger than those of the other three relaxation peaks. The analysis of the material mixing ratio and the water absorption characteristics of the materials revealed that the water absorption of the straw fibers in the WPC had an important effect on the overall water absorption rate of the material. Moreover, as the slag powder content increased, the $A_{21}$ peak area exhibited a gradual decrease, and the peak area of K\#15 was $28.62 \%$ lower than that of K\#0. The measurement results suggest that the presence of inorganic fillers changed the distribution and overlapping mode of the straw fibers and reduced the connection chain of water intrusion. The analysis of the $A_{23}$ and $A_{24}$ peak areas of the four specimens revealed that with increasing slag powder content, the sum of the two peak areas was still small. Among the four specimens, the K\#10 and K\#15 specimens showed the $A_{24}$ peak, indicating that large pores in the composite material appeared and gradually increased, which meant that with the increase of the slag powder, the powder agglomerated. The test results were close to the research results of Ismaeilimoghadam et al. (2016). At the same time, it was found that for the $\mathrm{K} \# 0, \mathrm{~K} \# 5, \mathrm{~K} \# 10$, and $\mathrm{K} \# 15$ specimens, when the water was absorbed for $216 \mathrm{~h}$, the peak area of $A_{23}$ was reduced by more than $40 \%$ compared with $792 \mathrm{~h}$, as shown by the data in the red frame in Table 4. The reason was that in the long moisture absorption process, on the one hand, the straw absorbed water and swelled, causing internal stress to increase, opening partially closed pores (Li 2017), and redistributing moisture in pores of some areas to cause pore size changes. In contrast, due to the hydration reaction of the slag powder (Jin et al. 2021), the pore water in some areas decreased or disappeared, which was manifested as the change of the $A_{23}$ peak area.

\section{Influence of Immersion Time on Pore Size Distribution of WPCs}

Figure 3 shows the pore radius distribution graph plotted by converting the $T_{2}$ spectra of WPCs mixed with different slag powder contents according to Eqs. 1 through 3 . Figure 3 shows the following: (1) The WPCs pore radii were mainly distributed between 1 $\mathrm{nm}$ and $250 \mathrm{~nm}$, and the pores with a radius greater than $250 \mathrm{~nm}$ accounted for a small proportion. (2) For pores of 1 to $2.5 \mathrm{~nm}$ radius, with increasing slag powder content, the pore volume gradually decreased. Moreover, for each specimen (which had a distinct mixing ratio), except for $\mathrm{K} \# 0$, the pore volume gradually decreased with increasing immersion time, and the corresponding pores were not observed in K\#15. (3) Pores of 2.5 to $10 \mathrm{~nm}$ and 10 to $25 \mathrm{~nm}$ accounted for the largest proportion and were the main area for the water entry and exit and water storage. The change in the pore volume should also have the greatest impact on the water resistance of the material. (4) For each specimen, except for $\mathrm{K \# 0}$, as the immersion time increased, the pores of 2.5 to $10 \mathrm{~nm}$ also showed a gradual decreasing trend in volume, and the largest pore volume was found at $72 \mathrm{~h}$. The pore volumes corresponding to $72 \mathrm{~h}$ and $792 \mathrm{~h}$ immersions were compared, and the maximum difference between the pore volumes was 20 to $27 \%$. The pore volume of the K\#0 specimen did not show large changes. With the change in the slag powder content, there were no changes in pore volume for all specimens under the same immersion time. (5) For pores of 10 to $25 \mathrm{~nm}$, the pore volume gradually increased with increasing water immersion time and increasing slag powder content. The pores of 25 to $100 \mathrm{~nm}$ and 100 to $160 \mathrm{~nm}$ also showed similar patterns. (6) For pores of 160 to $400 \mathrm{~nm}$, the pore volume accounted for a relatively small proportion and had a little impact on the water absorption property of the material. 


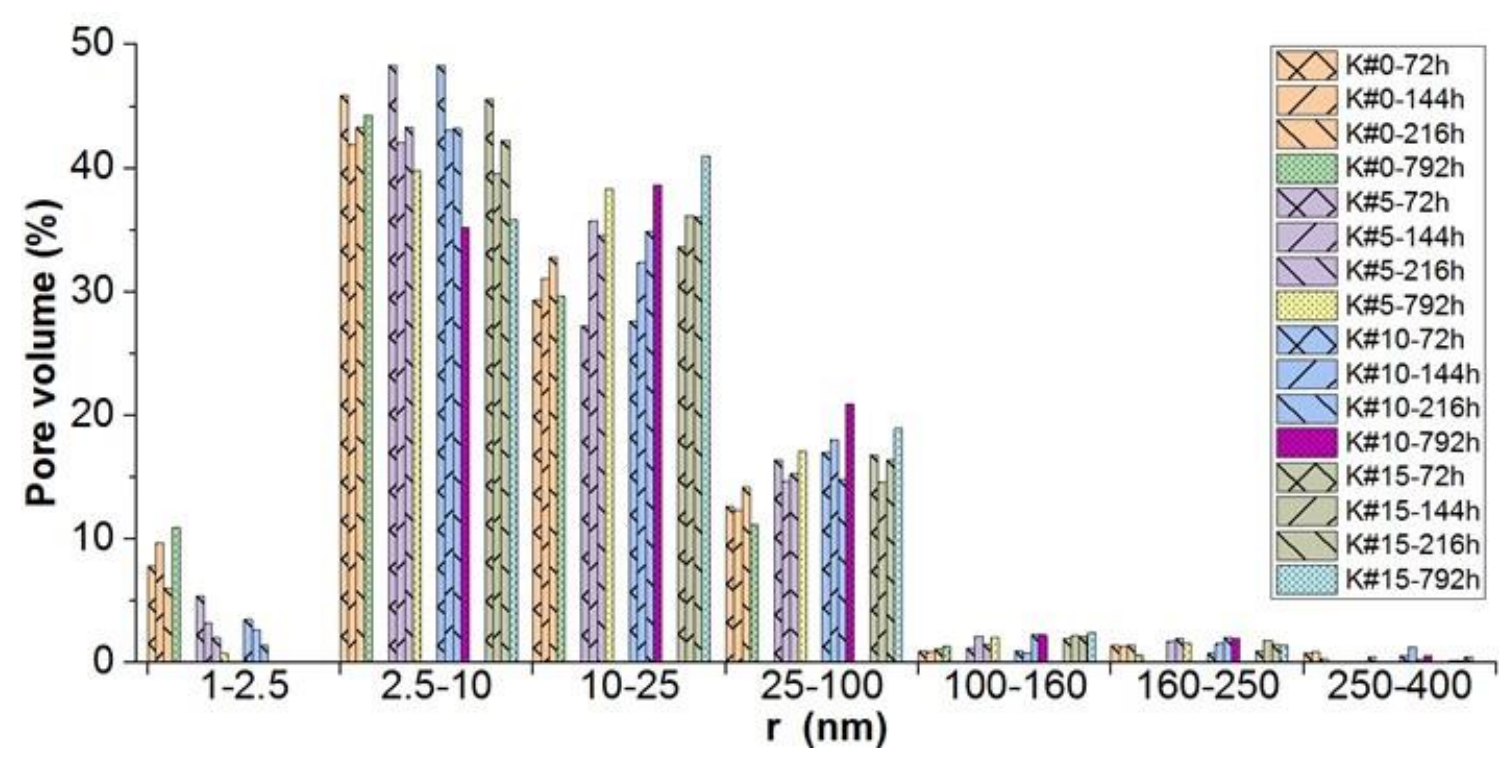

Fig. 3. Distribution graph of pore radius of 1 to $400 \mathrm{~nm}$

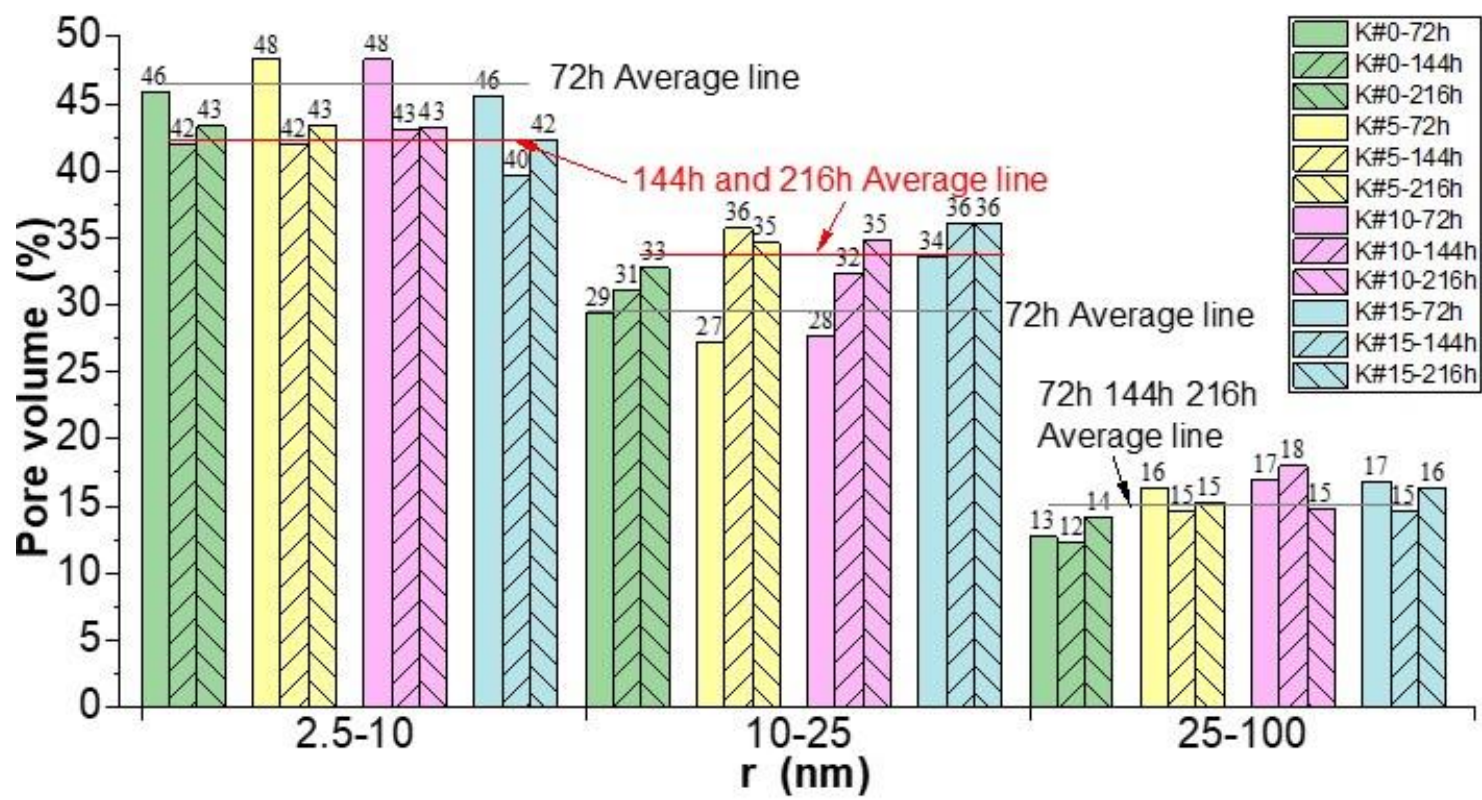

Fig. 4. Distribution graph of pore radius of 2.5 to $100 \mathrm{~nm}$ when composite was immersed for $72 \mathrm{~h}$, $144 \mathrm{~h}$, and $216 \mathrm{~h}$

Figure 4 shows the distribution graph of pores of 2.5 to $100 \mathrm{~nm}$ radius when the composite was immersed for 72 h, 144 h, and 216 h, and Fig. 5 shows the distribution graph of the pores of 2.5 to $100 \mathrm{~nm}$ when the composite was immersed for $216 \mathrm{~h}$ and $792 \mathrm{~h}$. From Fig. 4, the following patterns were found. When the composite was immersed for $72 \mathrm{~h}, 144$ $\mathrm{h}$, and $216 \mathrm{~h}$, for each immersion time, with the change in the slag powder content, the pore volume of each specimen showed minor changes, and the volume difference was within $4 \%$. This indicates that as the immersion time increased, moisture continued to fill the composite pores. For the pore radius range of 2.5 to $10 \mathrm{~nm}$, the highest volume was found after $72 \mathrm{~h}$ immersion, after which the volume was reduced. For the pore radius range of 10 to $25 \mathrm{~nm}$, with increasing immersion time, the pore volume increased; for the pore radius range of 25 to $100 \mathrm{~nm}$, the pore volume increased, although the change was small. In the 
WPCs, the water absorption rate of the PVC substrate was low, and the wheat straw had strong water absorption, which is the main cause of the water absorption of WPCs. In addition, the material interface bonding defects, inorganic powder water absorption, and other factors affect the water resistance of WPCs. Figure 3 shows that pores of $2.5 \mathrm{~nm}$ to $100 \mathrm{~nm}$ were the main area for the water entry, accounting for over $80 \%$ of pores volume of the WPCs, and were the main area for wheat straw, interface, and inorganic powder to absorb water. The comparison of K\#0, K\#5, K\#10, and K\#15 after 72 h, 144 h, and 216 h water immersions showed that the difference in the volumes of pores of 2.5 to $100 \mathrm{~nm}$ among the specimens was not large, indicating that the slag powder in this stage did not have a strong impact on the radius and volume of pores absorbing water.

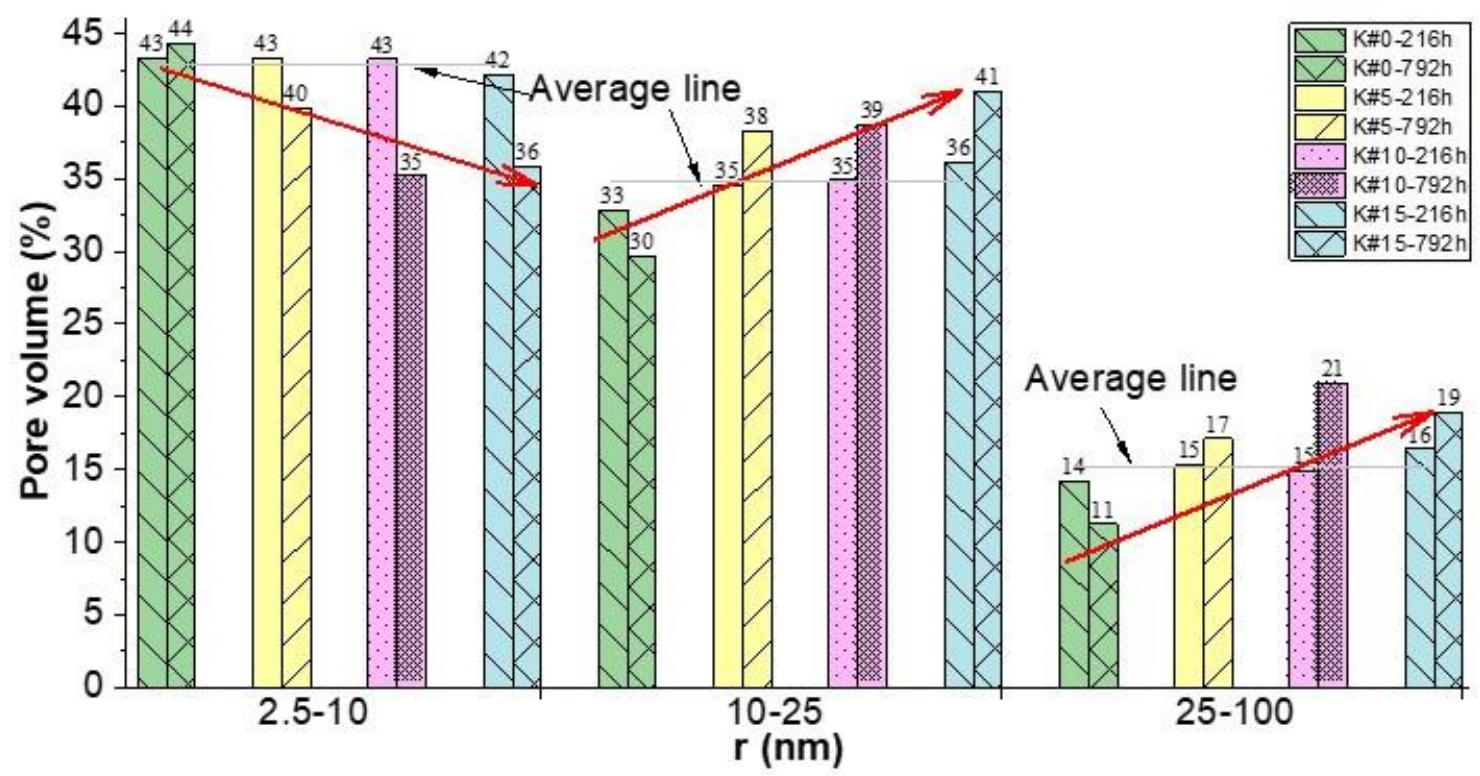

Fig. 5. Distribution graph of pore radius of 2.5 to $100 \mathrm{~nm}$ when composite was immersed for 216 $\mathrm{h}$ and $792 \mathrm{~h}$

Figure 5 shows that after the composite was immersed for $216 \mathrm{~h}$, the pore volume had changed substantially, for pores of 2.5 to $100 \mathrm{~nm}$. For the pores of 2.5 to $10 \mathrm{~nm}$, with increasing slag powder content, the pore volume decreased, and the maximum difference in the rate of change was $21.8 \%$. For the pores of 10 to $25 \mathrm{~nm}$ and 25 to $100 \mathrm{~nm}$, with increasing slag powder content, the pore volume of each specimen increased; moreover, the maximum differences in the change rate were $29 \%$ and $43.3 \%$, respectively. The changes in the composite immersed for $216 \mathrm{~h}$ were considerably different from those immersed for $72 \mathrm{~h}, 144 \mathrm{~h}$, and $216 \mathrm{~h}$. The analysis of the material composition of K\#0, $\mathrm{K} \# 5, \mathrm{~K} \# 10$, and K\#15 specimens showed that an increase in the slag powder content could reduce the volume of pores of 2.5 to $10 \mathrm{~nm}$ radius after the composite was immersed in water for $216 \mathrm{~h}$ and increase the volume of pores of 10 to $100 \mathrm{~nm}$. The above finding combined with the difference between the water absorption rate and the expansion rate of the material (Fig. 7) demonstrates that the slag powder incorporation changed the water distribution after the pores absorbed water and reached saturation. Figures 4 and 5 confirmed the significance of the difference from the perspective of the change in pore volume. 


\section{Analysis of the Slag Powder Influence on the WPC Water Absorption Rate, Expansion Rate, and Their Difference}

Figure 6 shows the variation trend of the water absorption rate and expansion rate of the WPCs with slag powder content, and Fig. 7 shows the difference between the water absorption rate and expansion rate of the corresponding material. Studies have shown that free hydroxyl groups exist on the wood fiber molecular chains. Under the action of water molecules, the hydrogen bonds between the molecular chains are opened to generate new free hydroxyl groups. This process allows the distance between the pores of the straw and the wood microfibrils to gradually increase, and the macroscopic manifestation is the expansion characteristics of straw and wood (Li et al. 2016).

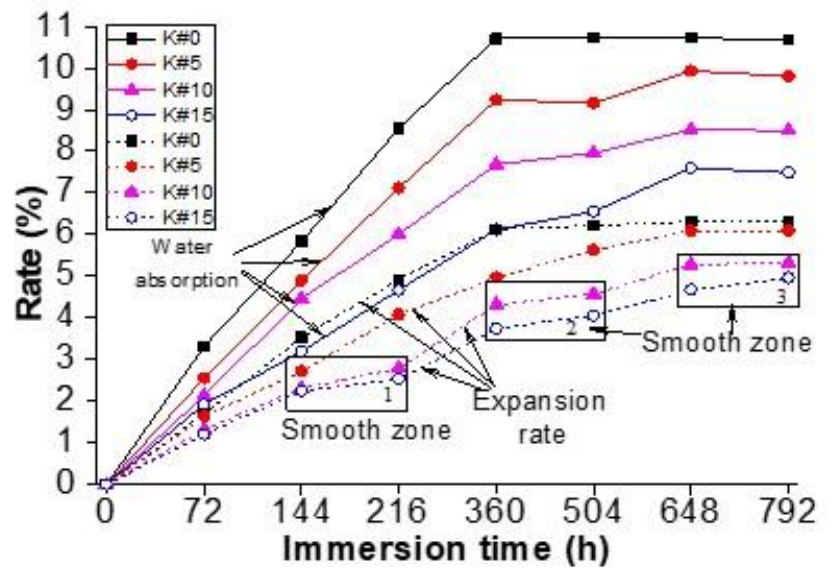

Fig. 6. The trends of material water absorption rate and expansion rate

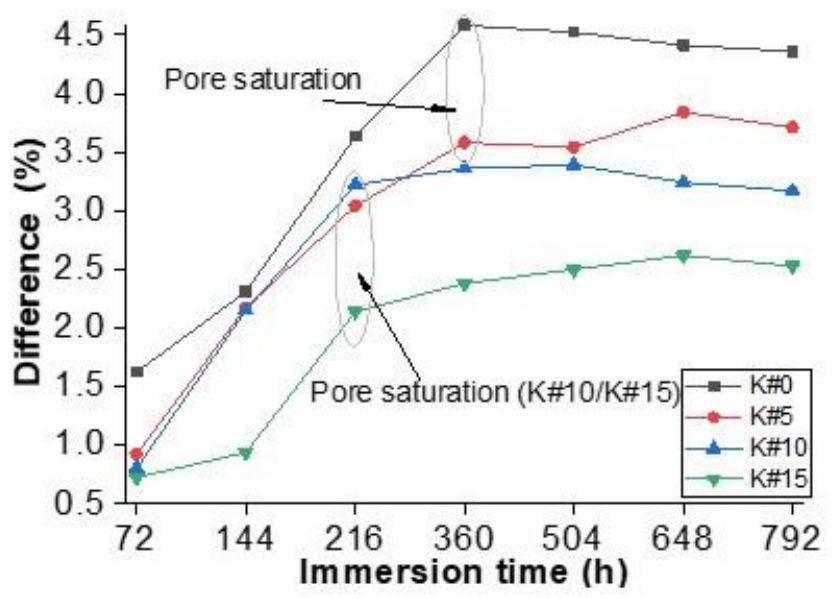

Fig. 7. The difference between material water absorption rate and expansion rate

As depicted in Fig. 6, with the increasing amount of slag powder, the water absorption rate and expansion rate of the material gradually decreased, and the slag powder improved the water resistance of the material. From the perspective of material composition analysis, after the slag powder is added, the slag powder particles block the direct overlap between some wheat straws because they are relatively small, have a large specific surface area, and are distributed between the entangled wheat straw fibers. Consequently, the wheat straws cannot form a complete fiber long chain for water absorption. Additionally, wheat straw has a small bulk density and a large volume ratio, 
and it is not easily completely covered by the PVC substrate, while the slag powder has small particles and a large specific surface area and can further reduce the pore volume after it is introduced in space between the wheat straw and PVC substrate. Moreover, the surface modification of slag powder by KH550 also improves the bonding performance with the PVC substrate interface. The order of the water resistance of materials was K\#15 $>\mathrm{K} \# 10>\mathrm{K} \# 5>\mathrm{K} \# 0$.

The analysis of the smooth zone shown in Fig. 6 showed that the expansion rates of smooth zones 1 and 2 were reduced, but the water absorption rate still increased. Subsequently, there was a steep rise, and the expansion rate increased rapidly. After smooth zone 3, K\#15 and K\#10 did not show large changes in the water absorption rate and expansion rate of the specimen, and the specimen reached a saturated state. This phenomenon is related to the hydration and hardening of the slag powder. After the ground slag powder maintains contact with water for a period, a slight hydration reaction will occur on the powder surface, so that some substances are dissolved and hydrated, forming C-S$\mathrm{H}$ gel and $\mathrm{Ca}(\mathrm{OH})_{2}$. However, further hydration is prevented by the low-permeability protective film on the surface of the slag glass body, so that water cannot enter the slag glass body (Liu et al. 2015), and the ions inside the slag cannot seep out, which affects the continuous hydration of the slag. Not only does the $\mathrm{Ca}(\mathrm{OH})_{2}$ product in the hydration process expand 1.98 times in volume, but new pores are added. These hydration effects cause expansion stress within the material, which reduces the bonding capability of the interface between the filler and the PVC substrate and causes microcracks formation. However, the WPC lacks an environment for the continuous hydration of the slag powder, and the hydration reaction is not sufficient; thus, the volume expansion is limited. Nevertheless, this limited expansion widens the channels and space for water transfer inside the material, and thus, intermittent volume expansion occurs on a macroscopic level.

Figure 7 shows that the difference between the water absorption rate and expansion rate of $\mathrm{K \# 0}$ became stable after the specimen was immersed in water for $360 \mathrm{~h}$. Based on this finding and the water absorption rate and expansion rate of the K\#0 specimen (Fig. 6), the specimen absorbed water and reached saturation within this period, and the volume did not increase. The difference between the water absorption rate and expansion rate of K\#5 became stable after immersion in water for $360 \mathrm{~h}$; the water absorption rate and expansion rate of K\#5 specimens increased slowly within this period, indicating that the volume of water absorbed within this period was not different than the volume growth rate of the composite. After K\#10 and K\#15 were immersed in water for $216 \mathrm{~h}$, the difference between the water absorption rate and expansion rate for both specimens was steady. Within this period, the water absorption rate and expansion rate of the K\#10 and K\#15 specimens continued to increase, indicating that the volumes of water absorbed by the K\#10 and K\#15 specimens were not different from the volume growth rates of the composites. Regarding the analysis of the material compositions of $\mathrm{K} \# 0, \mathrm{~K} \# 5, \mathrm{~K} \# 10$, and $\mathrm{K \# 15}$ specimens, it can be seen that when the slag powder content was more than $10 \%$, the slag powder allowed the WPC to reach pore saturation earlier. Therefore, the increased volume of material from water absorption was consistent with the volume growth rate of the material.

According to Figs. 7 and 6, when the pore water absorption of the WPC did not reach saturation, a part of the absorbed water filled the material pores (the volume was not increased); moreover, a part of the water entered the fibrils, microfibrils, and fibril gaps of adjacent fibers and formed new hydrogen bonds with free hydroxyl groups. The hydroxyl binding process increases the distance between the molecular chains, showing an increase in the material volume macroscopically. When the WPC pores are saturated, the absorbed 
water mainly increases the tiny distance between the wood fiber molecular chains, and the increased volume of the material from water absorption is consistent with the volume expansion of the material. According to the Brunauer-Emmett-Teller (BET) adsorption theory (Chauhan et al. 2001), the specific surface area of the pores of the straw cell wall is relatively large; the water entering the wood fiber first undergoes monolayer adsorption with the cell wall pore, and then multi-layer adsorption occurs. The difference between the water absorption and swelling rate of the material, shown in Fig. 7, correlates with the water absorption process shown by the BET theory.

The comparison of the water absorption rate and expansion rate, shown in Fig. 6, reveals that the slag powder reduced the transport and storage space of water molecules. The results shown in Fig. 7 and the changes in pore size distribution shown in Fig. 5 could be mutually confirmed by the experimental results. After the composite was immersed for $216 \mathrm{~h}$, the volume of pores of 2.5 to $100 \mathrm{~nm}$ radius changed substantially, the volume of small pores of 2.5 to $10 \mathrm{~nm}$ decreased, and the volume of macropores of 10 to $100 \mathrm{~nm}$ increased, indicating that wheat straw absorbed water and expanded, and the pore size of the material increased.

\section{CONCLUSIONS}

1. According to the $\mathrm{H}$ proton transverse relaxation time and its inversion spectrum, the measured porosity had a small difference from the measurement result of the weighing method, indicating that the results of NMR analysis of water absorption characteristics of wood-plastic composites were reliable. However, high-content magnetic substances had a great impact on the LF-NMR measurement results.

2. With the extension of the immersion time of the material, the relaxation time corresponding to different peak areas showed different changes. With the increase in the content of inorganic fillers, the inorganic fillers changed the distribution and lap pattern of the wheat straw fibers, reducing the connection chain of moisture intrusion. When the content was greater than $10 \%$, large pores appeared in the composite material and gradually increased, which meant with the increase in slag powder, the powder agglomerated.

3. According to the pore size distribution map obtained at different immersion times, the findings could clearly reflect the water transmission and pore volume changes in the composite material at different time periods. The pore radius range of $2.5 \mathrm{~nm}$ to 100 $\mathrm{nm}$ was the main space for wheat straw, interface and inorganic powder to absorb water. When the immersion time was less than $216 \mathrm{~h}$, there was little difference in the pore volume of the composite material in the pore radius range of $2.5 \mathrm{~nm}$ to $100 \mathrm{~nm}$, indicating that the slag powder had little effect on the pore radius and pore volume of the composite material at this stage. When the immersion time was longer than $216 \mathrm{~h}$, the pore volume of the composite material in the pore radius range of $2.5 \mathrm{~nm}$ to $10 \mathrm{~nm}$ decreased, and the pore volume of the radius of $10 \mathrm{~nm}$ to $100 \mathrm{~nm}$ increased, but the peak area of $\mathrm{A}_{21}$ was still the largest, indicating that the incorporation of the slag powder had changed the pore structure of the wood-plastic composite material, but not the water absorption characteristics of the wheat straw fiber in the wood-plastic composite material. The incorporation of slag powder could reduce the overall water 
absorption of the material and make the pores of the composite material become saturated faster.

4. The pore size distribution and volume change law obtained through LF-NMR were able to confirm the results displayed by the water absorption rate, expansion rate, and the difference between the two.

\section{ACKNOWLEDGMENTS}

This work was supported by Xingjiang Regional Cooperative Innovation in Autonomous Region (2019E0241) and Nanjing Agricultural University-Xinjiang Agricultural University Joint Fund (Project No. 2018-6), Xinjiang Key Laboratory of Hydraulic Engineering Security and Water Disasters Prevention.

\section{REFERENCES CITED}

Chauhan, S. S., Aggarwal, P., Karmarkar, A., and Pandey, K. K. (2001). "Moisture absorption behaviour of esterified rubber wood (Hevea brasiliensis)," Holz als Rohund Werkstoff 59, 250-253. DOI: 10.1007/s001070000152

Cheng, Q., and Shaler, S. (2010). "Moisture movement in wood polypropylene composites," European Journal of Wood and Wood Products 68, 463-468. DOI: 10.1007/s00107-009-0391-4

Defoirdt, N., Gardin, S., Van den Bulcke, J., and Acker, J. V. (2010). "Moisture dynamics of WPC and the impact on fungal testing," International Biodeterioration \& Biodegradation 64(1), 65-72. DOI: 10.1016/j.ibiod.2009.07.010

Diamond, S. (2000). "Mercury porosimetry: An inappropriate method for the measurement of pore size distributions in cement-based materials," Cement and Concrete Research 30(10), 1517-1525. DOI: 10.1016/S0008-8846(00)00370-7

Grunewald, E., and Walsh, D. (2013). "Multiecho scheme advances surface NMR for aquifer characterization," Geophysical Research Letters 40, 6346-6350. DOI:10.1002 /2013GL057607

Homkhiew, C., Ratanawilai, T., and Thongruang, W. (2014). "Long-term water absorption and dimensional stability of composites from recycled polypropylene and rubberwood flour," Journal of Thermoplastic Composite Materials 29(1), 74-91. DOI: 10.1177/0892705713518789

Ismaeilimoghadam, S., Masoudifar, M., Nosrati, B., and Shamsian, M. (2016). "Effects of inorganic nanoparticles on mechanical and morphological properties of wood flour-polypropylene nano composites," DREWNO 59(196), 127-137. DOI: 10.12841/wood.1644-3985.127.09

Jin, Q., Zhu, L., Madiniyeti, J., He, C., and Li, L. (2021). "Influence of active inorganic fillers on the physical and mechanical properties of polyvinyl chloride wood-plastic composites when immersed," BioResources 16(1), 789-804. DOI: 10.15376/biores.16.1.789-804

Kaboorani, A., and Englund, K. R. (2011). "Water sorption and mechanical performance of preheated wood/thermoplastic composites," Journal of Composite Materials 45(13), 1423-1433. DOI: 10.1177/0021998310382317 
Kallbom, S., Lillqvist, K., Spoljaric, S., Seppala, J., Segerholm, K., Rautkari, L., Hughes, M., and Walinder, M. (2020). "Effects of water soaking-drying cycles on thermally modified spruce wood-plastic composites," Wood and Fiber Science 52(1), 2-12. DOI: $10.22382 / w f s-2020-002$

Korb, J. P. (2009). "NMR and nuclear spin relaxation of cement and concrete materials," Current Opinion in Colloid and Interface Science 14(3), 192-202. DOI: 10.1016/j.cocis.2008.10.004

Lin, H., Li, R., Li, D., Huang, Z., and Yang, W. (2020). "Hydrophobic wood flour derived from a novel $\mathrm{p}-\mathrm{TsOH}$ treatment for improving interfacial compatibility of wood/HDPE composites," Cellulose 27, 4053-4065. DOI: 10.1007/s10570-02003046-4

Liu, R. G., Ding, S. D., and Yan, P. Y. (2015). "Influence of hydration environment on the characteristics of ground granulated blast furnace slag hydration products," Bulletin of the Chinese Ceramic Society 34(6), 1594-1599. DOI: 10.16552/j.cnki.issn1001-1625.2015.06.028

Li, X. (2017). The Pore Distribution and Water Movement in Wood Studied by Time Domain Nuclear Magnetic Resonance Technique, Ph.D. Dissertation, Inner Mongolia Agricultural University, Hohhot, China.

Li, X., Wang, X., and Zhang, M. (2016). "Molecular dynamics of water in wood studied by fast field cycling nuclear magnetic resonance relaxometry," BioResources 11(1), 1882-1891. DOI: 10.15376/biores.11.1.1882-1891

Muller, A. C. A., and Scrivener, K. L. (2017). "A reassessment of mercury intrusion porosimetry by comparison with ${ }^{1} \mathrm{H}$ NMR relaxometry," Cement and Concrete Research 100, 350-360. DOI: 10.1016/j.cemconres.2017.05.024

Najafi, S. K., Tajvidi, M., and Chaharmahli, M. (2006). "Long-term water uptake behavior of lignocellulosic-high density polyethylene composites," Journal of Applied Polymer Science 102(4), 3907-3911. DOI: 10.1002/app.24172

Provencher, S. W. (1982a). "A constrained regularization method for inverting data represented by linear algebraic or integral equations," Computer Physics Communications 27(3), 213-227. DOI: 10.1016/0010-4655(82)90173-4

Provencher, S. W. (1982b). "CONTIN: A general purpose constrained regularization program for inverting noisy linear algebraic and integral equations," Computer Physics Communications 27(3), 229-242. DOI: 10.1016/0010-4655(82)90174-6

Qi, R., He, C., and Jin, Q. (2019). "Effect of acrylate-styrene-acrylonitrile on the aging properties of eucalyptus/PVC wood-plastic composites," BioResources 14(4), 91599168. DOI: 10.15376/biores.14.4.9159-9168

Sun, Z., and Scherer, G. W. (2010). "Pore size and shape in mortar by thermoporometry," Cement and Concrete Research 40(5), 740-751. DOI:

10.1016/j.cemconres.2009.11.011

Wang, Q., Wang, D., and Chen, H. (2017). "The role of fly ash microsphere in the microstructure and macroscopic properties of high-strength concrete," Cement and Concrete Composites 83, 125-137. DOI: 10.1016/j.cemconcomp.2017.07.021

Wang, X., Peng, Y., Jike, N., and Zeng, Q. (2019). "MIP-induced pore structure alterations of cement-based materials," Journal of the Chinese Ceramic Society 47(11), 1521-1526. DOI: 10.14062/j.issn.0454-5648.2019.11.01

Zhao, H., Qin, X., Liu, J., Zhou, L., Tian, Q., and Wang, P. (2018). "Pore structure characterization of early-age cement pastes blended with high-volume fly ash," 
Construction and Building Materials 189, 934-946. DOI:

10.1016/j.conbuildmat.2018.09.023

Zhao, H., Wu, X., Huang, Y., Zhang, P., Tian, Q., and Liu, J. (2019). "Investigation of moisture transport in cement-based materials using low-field nuclear magnetic resonance imaging," Magazine of Concrete Research Online, 1-19. DOI: 10.1680/jmacr.19.00211

Zhao, Z., Zhang, Q., and Wang, J. (2020). "Properties comparison of coextruded and uncoextruded wood plastic composites under high temperature accelerated water uptake," Polymer Composites 41(7), 2616-2624. DOI: 10.1002/pc.25560

Zhou, C. S., Ren, F. Z., Zeng, Q., Xiao, L., and Wang, W. (2018). "Pore-size resolved water vapor adsorption kinetics of white cement mortars as viewed from proton NMR relaxation," Cement and Concrete Research 105, 31-43. DOI: 10.1016/j.cemconres.2017.12.002

Zhuo, G., Zhang, X., Jin, X., Wang, M., Yang, X., and Li, S. (2020). "Effect of different enzymatic treatment on mechanical, water absorption and thermal properties of bamboo fibers reinforced poly (Hydroxybutyrate-co-Valerate) biocomposites," Journal of Polymers and the Environment 28, 2377-2385. DOI:

10.1007/s10924-020-01781-0

Article submitted: January 12, 2020; Peer review completed: March 27, 2021; Revised version received and accepted: April 16, 2021; Published: April 23, 2021.

DOI: $10.15376 /$ biores. 16.2.4064-4080 